\title{
Electrodeposition study of the Cu-Zn-Mo system in citrate/sulfate medium
}

\author{
Hugo Sousa Santos ${ }^{1 \oplus}$, Alessandra Alves Correa ${ }^{1 \oplus}$, Murilo Fernando Gromboni²® ${ }^{\oplus}$, Lucia Helena Mascaro ${ }^{1+\infty}$
}

1.Federal University of São Carlos (UFSCar), Department of Chemistry, Km 235 Washington Luís Hw, São Carlos, São Paulo, Brazil

2.University of São Paulo (USP), Institute of Chemistry, 400 Trabalhador São Carlense Ave, São Carlos, São Paulo, Brazil

+Corresponding author: Lucia Helena Mascaro, phone: +55 16 33519698, email address: lmascaro@ufscar.br

\section{ARTICLE INFO}

Article history:

Received: January 16, 2019

Accepted: August 3, 2019

Published: November 20, 2019

\section{Keywords:}

1. electrodeposition

2. Cu-Zn-Mo system

3. composite

4. alloy

5. intermetallic phases

6. molybdenum oxides
ABSTRACT: Alloys and composites that contain molybdenum have been studied due to their excellent properties, such as corrosion resistance and catalytic activity. In this work, the parameters for $\mathrm{Cu}-\mathrm{Zn}-\mathrm{Mo}$ system electrodeposition were studied, such as deposition potentials and concentration of electroactive species. The deposition potentials were examined using cyclic voltammetry and anodic linear stripping voltammetry (ALSV), the deposit morphology was evaluated using scanning electron microscopy (SEM) and crystallographic characterization was carried out for X-ray diffraction (XRD). The voltammetry studies indicated codeposition of the metals in potentials more negative than -1.2 $\mathrm{V}$, and a potential deposition at $-1.5 \mathrm{~V}$ was chosen. The coatings presented morphology compact with small agglomerated particles with cauliflower structures, and the content of molybdenum, copper, and zinc ranged from 5 to $8 \%, 30$ to $40 \%$ and 20 to $28 \%$, respectively.

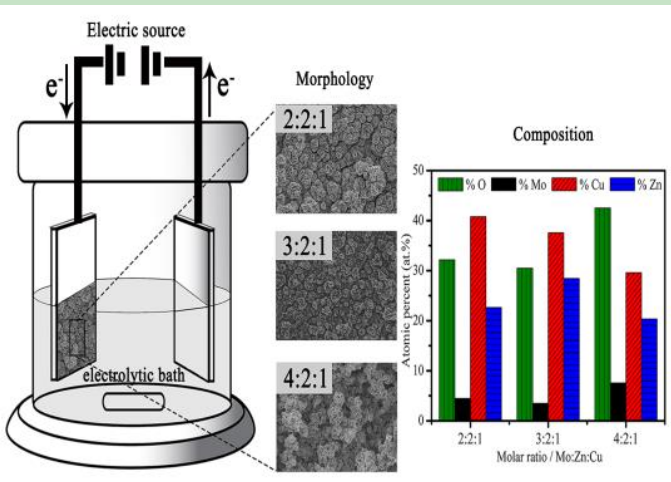

The Mo-Zn-Cu system electrodeposition was studied. The coatings had cauliflower morphology and the content $\mathrm{Mo}, \mathrm{Cu}$ and $\mathrm{Zn}$ ranged from 5 to $8 \%, 30$ to $40 \%$ and 20 to $28 \%$, respectively.

\section{Introduction}

Alloys and composites of zinc (Zn) and copper $(\mathrm{Cu})$ commonly called brass have excellent properties such as mechanical strength, malleability and resistance against corrosion; in addition, they are considered to be weakly harmful to the environment ${ }^{1,2}$. On the other hand, molybdenum (Mo) compounds and oxides are also relevant in terms of their excellent resistance against corrosion and electrocatalytic activities ${ }^{3-10}$. Therefore, an alloy/composite composed of $\mathrm{Cu}, \mathrm{Zn}$ and Mo may have applicability as corrosion resistant coating and electrocatalytic material. Methods that use thermal energy, such as thermal spraying ${ }^{11}$ and melting metal in a vacuum or inert atmosphere $^{12}$, are utilized to get these materials, but both methods are costly and expend a great deal of energy ${ }^{13}$. A reasonable option is electroplating because it is a generally simple technique, inexpensive and broadly utilized in the production of composites, metallic coatings, alloys and semiconductors on different substrates ${ }^{14,15}$.

Recent research shows the possibility of Mo deposition with $\mathrm{Zn}$ and $\mathrm{Cu}^{14,16-18}$. In these studies, the $\mathrm{Zn}$-Mo composite is proposed as a corrosion resistant coating with low danger and environmentally friendly, in contrast to other anticorrosive alloys containing cadmium and chromium. One of the announced methods for getting this material was by potentiostatic deposition at $-1.4 \mathrm{~V}$, where an amount of $70 \% \mathrm{~m} / \mathrm{m}$ Mo was incorporated on the surface of the coating $^{14}$. Kazimierczak et al., in another study, 
obtained Zn-Mo coatings with up to $14 \%$ Mo and showed that the deposits with more than $1 \%$ Mo had amorphous or nanocrystalline characteristics ${ }^{16}$. In their turn, $\mathrm{Cu}$-Mo compounds can be used as heat sinks or heat diffusers in electronic devices. Gotou et al. ${ }^{17}$ studied this system and obtained coatings with up to $22 \% \mathrm{~m} / \mathrm{m}$ Mo with amorphous features, regardless of the amount of Mo in the coatings. Thus, a few studies have reported on $\mathrm{Cu}$ Mo and Zn-Mo binary composites; however, there has been no report of $\mathrm{Cu}-\mathrm{Zn}-\mathrm{Mo}$ ternary system obtained by electrodeposition. As previously mentioned, the combination of these three elements could be interesting as a corrosion resistant coating, as with the case of $\mathrm{Zn}-\mathrm{Cu}^{19-21}$ and $\mathrm{Zn}-\mathrm{Mo}^{14,16,18}$ alloys and composites. In addition, the introduction of Mo in these coatings should significantly improve the electrocatalytic properties for water electrolysis because the presence of Mo in the iron group's alloys and composites has been described as responsible for the reduction of the overpotential of the hydrogen evolution reaction ${ }^{10,22-24}$.

One of the issues in the electrodeposition of ternary systems is the stability and solubility of the salts used to formulate the deposition baths, which can be achieved by inserting specific complexing agents $^{25}$. However, aggressive and toxic complexes such as cyanides and chlorides are commonly used in the deposition baths of $\mathrm{Zn}$ and $\mathrm{Cu}$ alloys ${ }^{26}$. In the perspective of environmental problems, it is proposed to utilize a complexing agent that stabilizes the electroactive species and is minimally aggressive and toxic. A complexing agent that fits this proposition is citrate; it is nontoxic and forms electroactive complexes with $\mathrm{Cu}$ (II) and Mo (VI) over a wide $\mathrm{pH}$ range and with $\mathrm{Zn}$ (II) at acidic $\mathrm{pH}^{14,27,28}$.

Considering these facts, the objective of this study was to propose a bath for electrodeposition of the ternary system with $\mathrm{Cu}$ (II), Zn (II) and Mo (VI) ions and to verify the conditions for the occurrence of the co-deposition of these three elements. For this, several molar ratios of the ions in the deposition bath were studied using sodium citrate as complexing agent, and morphological, compositional and crystallographic characterizations of the coatings were performed.

\section{Experimental}

The chemicals used were $\mathrm{CuSO}_{4} \cdot 5 \mathrm{H}_{2} \mathrm{O}$ (> 99\%), $\mathrm{ZnSO}_{4} \cdot 7 \mathrm{H}_{2} \mathrm{O}$ (> 99\%), $\mathrm{Na}_{2} \mathrm{MoO}_{4}(>99 \%)$ and sodium citrate $\left(\mathrm{Na}_{3} \mathrm{C}_{6} \mathrm{H}_{5} \mathrm{O}_{7}>99 \%\right)$, all analytical grade and without any purification. The electrolytic baths were prepared by the dissolution of sodium citrate in ultrapure water treated in the Milli-Q system $\left(18.2 \mathrm{M} \Omega \mathrm{cm}^{-1}\right)$, followed by the addition of the salts of the metal ions. According to the work of Kazimierczak et al. ${ }^{16}$ and Slupska and $\mathrm{Ozga}^{29}$, which correlated the predominant $\mathrm{Cu}$ (II), Mo (VI) and Zn (II) species with respect to citrate concentrations and $\mathrm{pH}$ in the baths. For that all species to be electroactive in the baths the $\mathrm{pH}$ of the electrolyte should be between 3 and 5.5. Therefore, the $\mathrm{pH}$ of the electrolytic baths in this work was adjusted to 4 with sulfuric acid. The chemical composition of all baths is shown in Table 1.

Table 1. Chemical composition of the deposition baths used.

\begin{tabular}{|c|c|c|c|c|c|}
\hline Baths & $\begin{array}{c}{[\mathrm{Mo}(\mathrm{VI})] /} \\
\mathrm{mol} \mathrm{L}^{-1}\end{array}$ & $\begin{array}{l}{[\mathrm{Zn}(\mathrm{II})] /} \\
\mathrm{mol} \mathrm{L}^{-1}\end{array}$ & $\begin{array}{l}{[\mathrm{Cu}(\mathrm{II})] /} \\
\mathrm{mol} \mathrm{L}^{-1}\end{array}$ & $\begin{array}{l}\text { [Citrate]/ } \\
\text { mol L L }^{-1}\end{array}$ & $\begin{array}{c}{[\mathrm{Mo}(\mathrm{VI})]:[\mathrm{Zn}(\mathrm{II})]:} \\
{[\mathrm{Cu}(\mathrm{II})]}\end{array}$ \\
\hline 1 & - & 0.04 & 0.02 & 0.1 & $0: 2: 1$ \\
\hline 2 & 0.04 & - & 0.02 & 0.1 & $2: 0: 1$ \\
\hline 3 & 0.04 & 0.04 & 0.02 & 0.1 & $2: 2: 1$ \\
\hline 4 & 0.06 & 0.04 & 0.02 & 0.1 & $3: 2: 1$ \\
\hline 5 & 0.08 & 0.04 & 0.02 & 0.1 & $4: 2: 1$ \\
\hline
\end{tabular}

A platinum disk of $0.1 \mathrm{~cm}^{2}$ was used as the working electrode in the voltammetric studies. It was sanded in $0.25 \mu \mathrm{m}$ diamond paste and then remained in sonication for $5 \mathrm{~min}$ in isopropyl alcohol before being rinsed with deionized water. The coatings were also produced in 1010 carbon steel. For this, steel plates with exposed area of $2.6 \mathrm{~cm}^{2}$ were used as working electrodes. The plates were treated with 5\% sulfuric acid solution to remove the iron oxides. Then, they were rinsed with distilled water and sanded with sandpaper until the granulometry reached 600 , and finally 
they underwent basic degreasing in $\mathrm{NaOH}$ $3.0 \mathrm{~mol} \mathrm{~L}^{-1}$ for $2 \mathrm{~min}$. An $\mathrm{Ag}_{(\mathrm{s})}\left|\mathrm{AgCl}_{(\mathrm{s})}\right| \mathrm{Cl}^{-}$ (saturated $\mathrm{KCl}$ ) electrode and a high surface area $\mathrm{Pt}$ grid were used as reference and auxiliary electrodes, respectively.

The voltammetric studies were performed in the potentials range of 1.5 to $-1.5 \mathrm{~V}$ with a scan rate of $50 \mathrm{mV} \mathrm{s}^{-1}$, three cycles were performed in each measurement. The deposition potentials were evaluated through cyclic voltammetry at different cathodic inversion potentials in the range of -1.0 to $-2.0 \mathrm{~V}$ with a scan velocity of $50 \mathrm{mV} \mathrm{s} \mathrm{s}^{-1}$. Electrochemical stripping analyses in the range of -1.0 to $1.0 \mathrm{~V}$ were obtained for the coatings deposited in $-1.6,1.75$ and $-2.0 \mathrm{~V}$ in the binary baths of Mo (VI) and $\mathrm{Cu}$ (II) (bath 4) and Zn (II) and $\mathrm{Cu}$ (II) (bath 5). The stripping analyses were carried out in $0.1 \mathrm{~mol} \mathrm{~L}^{-1}$ sodium citrate solution at $\mathrm{pH} 4$. The depositions were performed at constant potential in the range of -1.2 to $-2.0 \mathrm{~V}$ for $1800 \mathrm{~s}$. All measurements were performed at $25^{\circ} \mathrm{C}$. The morphologies of the coatings were evaluated using scanning electron microscopy (SEM) with highresolution field emission using an FE-SEM, ZEISS SUPRA 35, and the composition was analyzed through X-ray dispersive energy (EDX) spectroscopy using a FEI-XL30-FEG with an Oxford Instruments-Link ISIS 300 detector. The structural characterizations were performed using an X-ray diffractometer (Rigaku-DMax2500PC) with $\mathrm{Cu} \mathrm{K} \alpha=1.5406 \AA, 40 \mathrm{kV}$ voltage, theta-2theta configuration and a scan angle of $20-80^{\circ}$ with a scanning speed of $2 \% \mathrm{~min}$.

\section{Results and discussion}

\subsection{Voltammetric studies}

The cathodic voltammograms for the baths with 2:2:1, 3:2:1 and 4:2:1 molar ratios of $\mathrm{Mo}(\mathrm{VI})$ : $\mathrm{Zn}$ (II): $\mathrm{Cu}(\mathrm{II})$ on $\mathrm{Pt}$ are shown in Fig. 1. The peak $\mathrm{c} 1$ at $0.15 \mathrm{~V}$ and $\mathrm{c} 2$ at $-0.1 \mathrm{~V}$ could be attributed to underpotential deposition (UPD) and bulk deposition of copper from the non-complexed $\mathrm{Cu}^{2}$ ${ }^{+}$ions, respectively ${ }^{30}$. This is possible because the concentration of citrate $\left(0.1 \mathrm{~mol} \mathrm{~L}^{-1}\right)$ in these baths was less than the total metal-ion concentration, which is evidence of the occurrence of Mo (VI), Zn (II) and $\mathrm{Cu}$ (II) noncomplexed species. It was also observed that peaks $\mathrm{c} 1$ and $\mathrm{c} 2$ presented higher cathodic currents when the concentration of molybdate was increased in the baths. Since the
molybdenum(VI) citrate complexes are more stable that copper (II) citrate complexes in the $\mathrm{pH}$ used, the increase of the concentration of $\mathrm{MoO}_{4}{ }^{2+}$ ions led to a higher concentration of free $\mathrm{Cu}^{2+}$ ions in the bath ${ }^{31,32}$. The increase of the Mo (VI) concentration caused a considerable increase in the peak current $\mathrm{c} 3$ in the region of $-0.8 \mathrm{~V}$, which was attributed to the deposition of molybdenum oxides/hydroxides (Fig. S1b). The peaks c4 and c5 were due to the reduction of $\mathrm{Cu}$ (II) and $\mathrm{Zn}$ (II) complexed with citrate, respectively (Fig. S1). The curves in Fig. 1 indicate that the cathodic current in potentials more negative than $-1.25 \mathrm{~V}$ increased more significantly in the bath with a higher concentration of $\mathrm{MoO}_{4}{ }^{2-}$ (curve 3 ). This current is due to the evolution of $\mathrm{H}_{2}$, which is facilitated by the higher amount of Mo oxides/hydroxides deposited that is a catalytic species for hydrogen evolution reaction (HER) $)^{33}$. In conclusion, an increase of $\mathrm{MoO}_{4}{ }^{2-}$ concentration in the baths facilitates the deposition of molybdenum species; however, it leads to a higher evolution of hydrogen, which can lead to lower deposition efficiency and poor structure of the coatings.

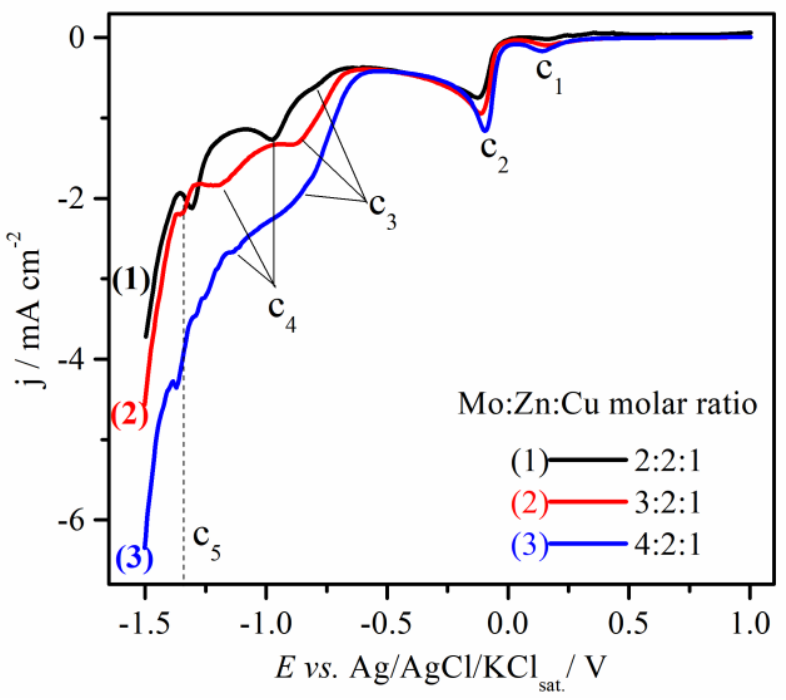

Figure 1. Cathodic voltammograms on Pt for baths Mo: $\mathrm{Zn:} \mathrm{Cu}$ of molar ratios (1) 2: 2: 1 (bath 6), (2) 3: 2: 1 (bath 7) and 4: 2: 1 (bath 8) at $\mathrm{T}=25^{\circ} \mathrm{C}$.

To find the best cathodic deposition potentials, a study was performed on different inversion cathodic potentials in the 2:2:1 Mo: $\mathrm{Zn}: \mathrm{Cu}$ bath (bath 6), as shown in Fig. 2a. From $-1.3 \mathrm{~V}$, the currents were very high due to the HER (graph inserted in Fig. 2a), which made it difficult to visualize the processes; therefore, the study focused on the more positive potential regions. 

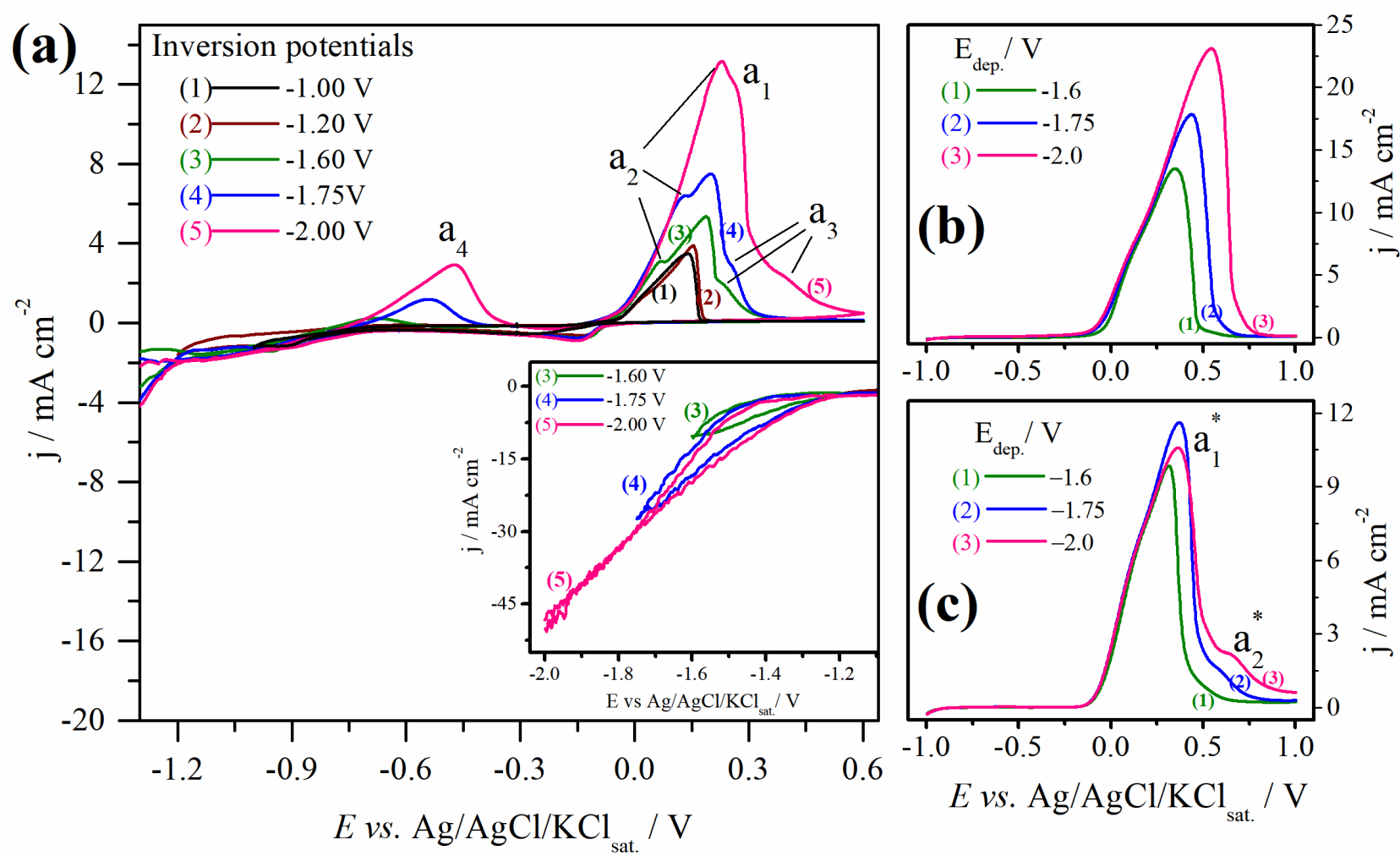

Figure 2. (a) Voltammograms on Pt for bath 3 of 2:2:1 molar ratio of Mo: $\mathrm{Zn}$ : $\mathrm{Cu}$ at inversion potentials -1.0V (line 1), 1.2 V (line 2), -1.6 (line 3), -1.75 V (line 4) and -2.0 V (line 5). (b) Stripping voltammetry curves for the coatings obtained on Pt in the bath 1 at $-1.6,-1.75$ and $-2.0 \mathrm{~V}$ (b) stripping voltammetry curves for the coatings obtained on Pt in the bath 2 at $-1.6,-1.75$ and $-2.0 \mathrm{~V}$ at $\mathrm{T}=25{ }^{\circ} \mathrm{C}$.

In the inversion potentials at -1.0 (line 1) and $1.2 \mathrm{~V}$ (line 2), only a cathodic and an anodic peak in the range of potentials of -0.25 to $0.25 \mathrm{~V}$ were identified as being attributed to deposition and dissolution of $\mathrm{Cu}$. From the potential of inversion of $-1.6 \mathrm{~V}$, a peak (a2) attributed to the dissolution of zinc or zinc-rich phase appeared, and for the more negative potentials $(-1.75$ and $-2.0 \mathrm{~V})$, larger anodic currents were presented, showing the favoring of the deposition of zinc at more negative potentials. The oxidation peaks in the range of 0 to $0.52 \mathrm{~V}$ potentials ( $\mathrm{a} 1, \mathrm{a} 2$ and $\mathrm{a} 3$ ) that appeared for the inverse potentials -1.6 (line 3), -1.75 (line 4) and $-2.0 \mathrm{~V}$ (line 5) are attributed to the dissolution of copper and copper-rich phases. It can be concluded from the voltammetric studies that zincrich $\mathrm{Cu}-\mathrm{Zn}$ phases and $\mathrm{Cu}-\mathrm{Mo}$ composites can be electrodeposited at highly negative potentials simultaneously with the HER from the proposed baths.

The phases related to the anode peaks in the region of potentials of 0.0 to $0.52 \mathrm{~V}$ (a1, a2 and a3) cannot be identified only by the voltammograms in Fig. 2a. Therefore, electrochemical stripping analyses were performed for deposits obtained in the $\mathrm{Zn}$ (II): $\mathrm{Cu}$ (II) (bath 4) and $\mathrm{Mo}$ (VI): $\mathrm{Cu}$ (II) (bath 5) binary baths. The coatings were deposited in $1.6,-1.75$ and $-2.0 \mathrm{~V}$ for $5 \mathrm{~min}$ on $\mathrm{Pt}$; these curves are shown in Fig. $2 b$ and c, respectively. The stripping curves for the coatings obtained in the bath containing only $\mathrm{Zn}$ (II) and $\mathrm{Cu}$ (II) presented a shoulder followed by a peak with high anodic current, which was attributed to the dissolution of $\mathrm{Cu}$ and $\mathrm{Cu}-\mathrm{Zn}$ phases. This result enables affirmation that peaks a1 and a 2 observed in the voltammograms of Fig. 2a were due to the dissolution of $\mathrm{Cu}-\mathrm{Zn}$ phases formed in potentials more negative than $-1.2 \mathrm{~V}$. The attribution of this anodic process to the dissolution of the $\mathrm{Cu}-\mathrm{Zn}$ is coherent because this process occurs in more negative potentials in comparison to the potential dissolution of the $\mathrm{Cu}$, motivated by the presence of $\mathrm{Zn}$ atoms.

Figure $2 b$ shows the stripping curves for the coatings obtained in the bath containing only Mo (VI) and $\mathrm{Cu}$ (II). In this voltammogram, one shoulder can be observed followed by the a ${ }^{*}$ peak attributed to the dissolution of $\mathrm{Cu}$ and $\mathrm{a} 2 *$ peak 
shifted to more positive potentials attributed to the phase dissolution or intermetallic compound formed between $\mathrm{Cu}$ and Mo. The shift of the a2* peak to more positive potentials compared to the oxidation of $\mathrm{Cu}$ is coherent because Mo has passivating characteristics. In turn, this result indicates that the anodic process a3 in the voltammograms of Fig. 2a is due to dissolution of $\mathrm{Cu}$-Mo phases. The stripping curves confirm the assumption that $\mathrm{Cu}$, Mo and $\mathrm{Zn}$ containing intermetallic compounds can be formed from that bath at potentials more negative than the $\mathrm{Zn}$ reduction potential, together with HER.

\subsection{Physical characterization}

Aiming for future applications, the coatings were also produced in 1010 carbon steel and characterized by their morphologies, chemical compositions and crystalline structure. The amount of the $\mathrm{Mo}, \mathrm{Cu}$ and $\mathrm{Zn}$ in the coatings obtained at $1.5 \mathrm{~V}$ on 1010 steel in the 2:2:1, 3:2:1 and 4:2:1 molar ratios of Mo: $\mathrm{Zn}: \mathrm{Cu}$ are shown in Fig. 3. The amount of $\mathrm{Cu}$ was the largest of the three metals in the system, varying between 30 and $40 \%$ at/at, showing that copper is deposited preferentially in this deposition conditions. However, the increased deposition of Mo-oxidized species with increasing $\mathrm{MoO}_{4}{ }^{2-}$ concentration in the baths directly affected $\mathrm{Cu}$ deposition by reducing its content in the coatings. Large amounts of $\mathrm{Zn}$ were also deposited, and all coatings that exhibited 20 to $28 \%$ of these metal coatings had less than $10 \%$ of Mo; on the other hand, they had considerable amounts of oxygen (more than 30\% at). From Fig. 3, it is clear that an increase of the Mo content in coatings leads to an increase in the oxygen content, which is independent of the $\mathrm{Cu}$ or $\mathrm{Zn}$, indicating that the Mo in the coatings is in the form of oxides. To understand the influence of the deposition potential on the coatings' chemical composition, electrodepositions were performed in a potential range of -1.2 to $-1.9 \mathrm{~V}$ in the $4: 2: 1$ molar ratio (bath 5) on steel 1010. These data are presented in Fig. 4a without the oxygen contents. It is noticed that the higher Mo contents were deposited at potentials more positive than $-1.4 \mathrm{~V}$. However, in comparison to the $\mathrm{Cu}$ and $\mathrm{Zn}$ contents, the amount of Mo remained almost constant in all deposition potentials, showing that the applied overpotential has little influence on its electrodeposition. On the other hand, both $\mathrm{Cu}$ and $\mathrm{Zn}$ deposition are strongly dependent on the overpotential applied. At the potentials more positive than $-1.4 \mathrm{~V}$ the coatings consisted of approximately 70 to $75 \%$ of $\mathrm{Cu}$ and between 13 and $15 \%$ of $\mathrm{Zn}$, but in more negative potentials, the $\mathrm{Zn}$ deposition was favored, becoming the major component with approximately $54 \%$ in $-1.9 \mathrm{~V}$. Based in Fig. 1, it is possible to infer that copper deposition occurs via kinetically activated regime until the potential near $-1.2 \mathrm{~V}$, followed by a diffusion process at more negative potentials. It is agreement the fact that a smaller amount of copper was electrodeposited in more negative potentials. On the other hand, the electrodeposition of zinc was favored in potentials more negative than $-1.2 \mathrm{~V}$ due this process is activated kinetically. This shows that, depending on the excess potential applied, it is possible to obtain coatings with different compositions. For more positive potentials, $\mathrm{Cu}$ rich coatings and for more negative potentials, $\mathrm{Zn}$ rich coatings are obtained.

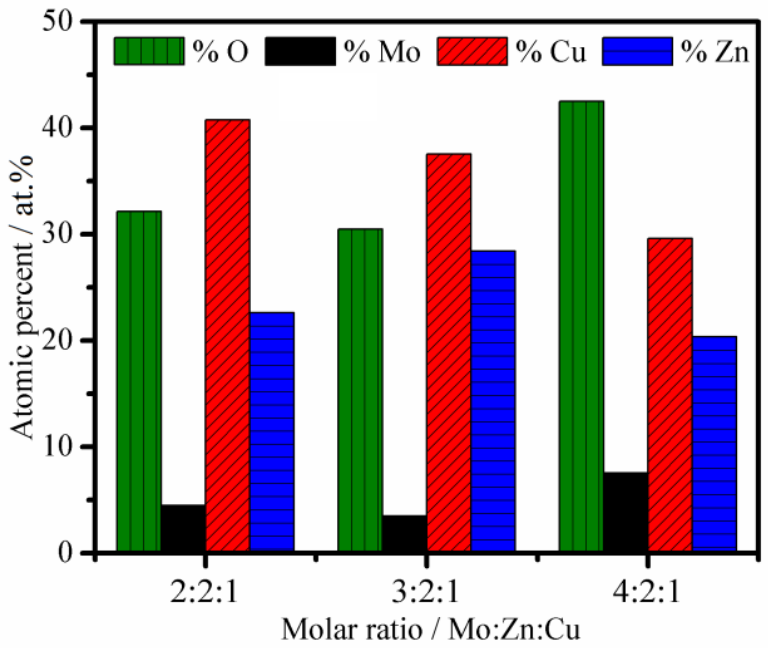

Figure 3. Composition for the coatings obtained in the baths of 2:2:1 (bath 3), 3:2:1 (bath 4) and 4:2:1 (bath 5) molar ratio of $\mathrm{Mo}: \mathrm{Zn}: \mathrm{Cu}$ at $-1.5 \mathrm{~V}$ on 1010 steel substrate. 
(a)

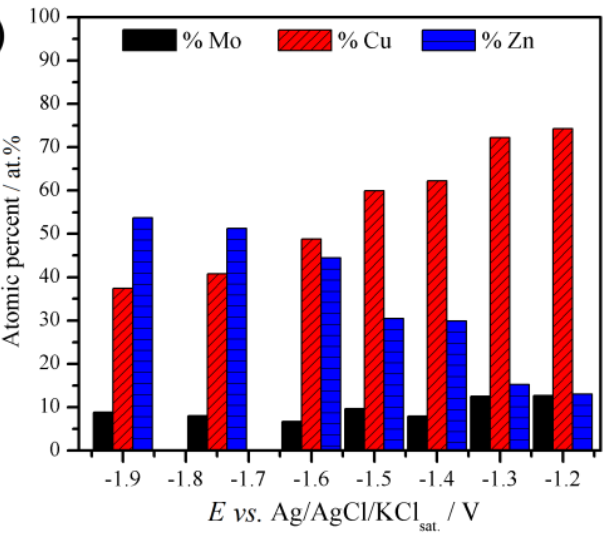

(b)

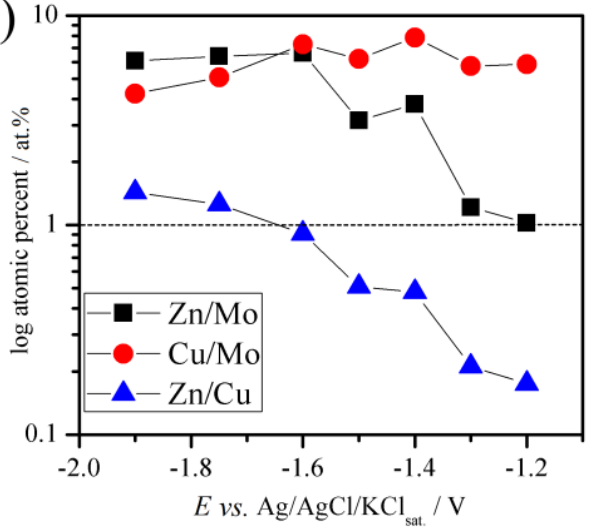

Figure 4. (a) Composition for the coatings obtained in the bath 5 of molar ratio Mo: $\mathrm{Zn}: \mathrm{Cu} 4: 2: 1$ in the range of deposition potentials of -1.2 to $-1.9 \mathrm{~V}$. (b) molar ratio between the metals in the coatings obtained in the bath 5 in the range of deposition potentials of -1.2 to $-1.9 \mathrm{~V}$ on 1010 steel substrate.

The profiles of the atomic ratios between the metals in the coatings are shown in Fig. $4 \mathrm{~b}$. Comparing the profiles of the $\mathrm{Zn} / \mathrm{Cu}$ and $\mathrm{Zn} / \mathrm{Mo}$ atomic ratios indicates that in the coatings obtained over the entire range of deposition potentials, the ratio values grew following the same pattern. The values of the $\mathrm{Zn} / \mathrm{Cu}$ ratio in the most positive potentials were less than 1.0 (higher $\mathrm{Cu}$ content) and remained thus until the potential of $-1.6 \mathrm{~V}$, where the $\mathrm{Cu}$ and $\mathrm{Zn}$ contents were similar. In the most negative potentials, $\mathrm{Zn}$ electrodeposition was favored, and the $\mathrm{Zn} / \mathrm{Cu}$ ratio values were greater than 1.0 (higher $\mathrm{Zn}$ content). The profile observed for the $\mathrm{Zn} / \mathrm{Mo}$ ratio was similar to that observed in $\mathrm{Zn} / \mathrm{Cu}$, indicating that the behavior of $\mathrm{Mo}$ and $\mathrm{Cu}$ deposition in relation to $\mathrm{Zn}$ deposition is similar; that is, in more positive potentials, $\mathrm{Cu}$ and $\mathrm{Mo}$ deposition is favored, and a smaller amount of $\mathrm{Zn}$ is deposited. According to the $\mathrm{Cu} / \mathrm{Mo}$ ratio profile, there was a small dependence between $\mathrm{Cu}$ and $\mathrm{Mo}$ on their deposition, as evidenced by the smaller variation of these values in comparison with the $\mathrm{Zn} / \mathrm{Mo}$ and $\mathrm{Zn} / \mathrm{Cu}$ ratios.

The coating surface morphologies obtained in the $-1.5 \mathrm{~V}$ potential are shown in Fig. 5a. They presented a relatively compact structure with small agglomerated particles forming larger cauliflowerlike structures; the small, smooth agglomerates on these structures are attributed to the oxides of Mo. The coating obtained in the 3:2:1 bath (Fig. 5b) showed structures similar to that of the 2:2:1 film but with a greater number of smooth structures between and on the grains. In contrast, the coating obtained in the 4:2:1 bath (Fig. 5c) presented less compactness and uniformity in its structure. The variation of the coating obtained in the bath with the higher concentration of Mo can be explained by taking into account the greater evolution of hydrogen that occurs with the electrodeposition of the coatings. This meant that the growth on the substrate was not uniform and compact. The greatest hydrogen evolution from bath 5 is proven by the cathodic voltammetry shown in Fig. 1, in which the cathodic current at $-1.5 \mathrm{~V}$ related to HER for this bath was considerably higher compared to the currents obtained in the other baths at the same potential. 

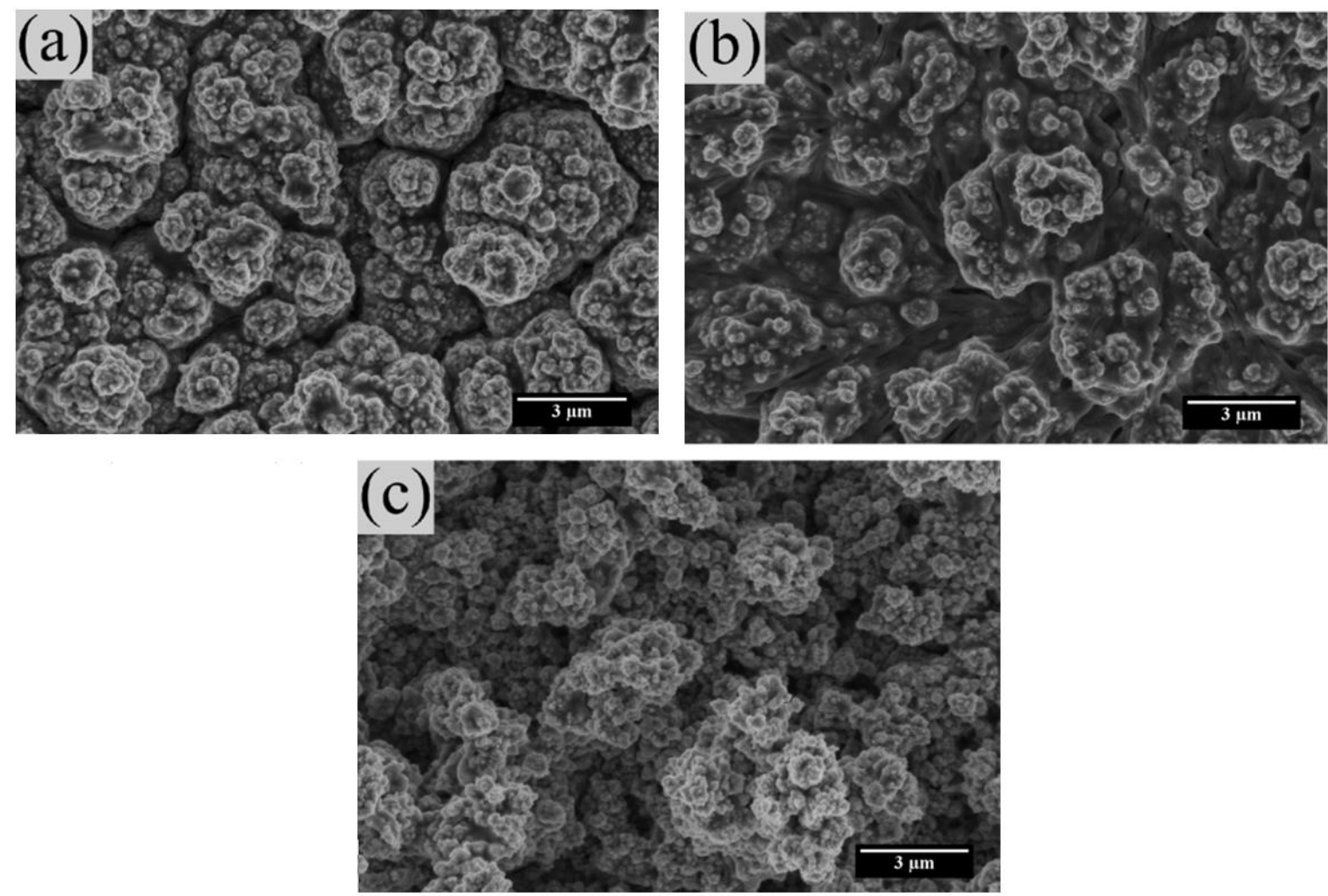

Figure 5. Surface morphologies obtained by SEM for coatings obtained at $-1.5 \mathrm{~V}$ in baths with Mo: $\mathrm{Zn}$ : Cu molar ratio of (a) 2:2:1 (bath 3), (b) 3:2:1 (bath 4) and (c) 4:2:1 (bath 5) on 1010 steel substrate.

The crystal structures were evaluated using Xray diffraction (XRD) and are shown in Fig. 6. The phases were identified with the aid of the crystallographic data patterns.

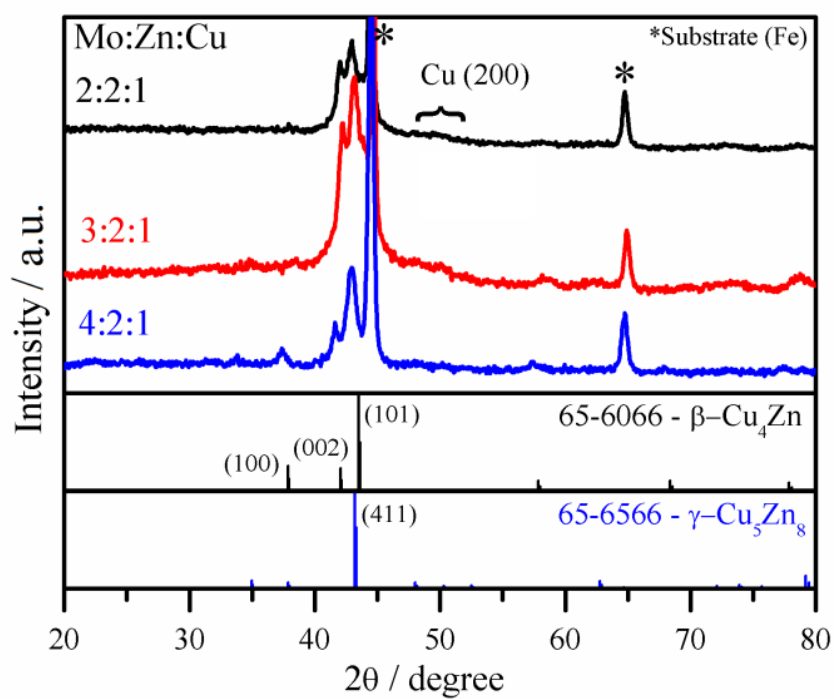

Figure 6. X-ray diffraction patterns for coatings obtained at $-1.5 \mathrm{~V}$ in baths of Mo: $\mathrm{Zn}$ : $\mathrm{Cu}$ molar ratios of $2: 2: 1$ (bath 3 , black line), 3:2:1 (bath 4 , red line) and 4:2:1 (bath 5, blue line) on 1010 steel substrate.
For all coatings, two phases of the $\mathrm{Cu}-\mathrm{Zn}$ alloy were identified, $\beta-\mathrm{Cu}-\mathrm{Zn}$ (PDF \# 65-6066) and $\gamma$ $\mathrm{Cu}-\mathrm{Zn}$ (PDF \# 65-6566). The equilibrium phase diagram for $\mathrm{Cu}-\mathrm{Zn}$ alloys shows that $\mathrm{Cu}$-rich phases, such as $\alpha-\mathrm{Cu}-\mathrm{Zn}(99-70 \% \mathrm{Cu})$ and $\beta-\mathrm{Cu}-$ $\mathrm{Zn}$ (with up to $48 \% \mathrm{Zn}$ ), and $\mathrm{Zn}$-rich phases, such as $\gamma-\mathrm{Cu}-\mathrm{Zn}\left(\mathrm{Cu}_{5} \mathrm{Zn}\right.$, with up to $\left.66 \% \mathrm{Zn}\right)$ and $\varepsilon-\mathrm{Cu}-$ $\mathrm{Zn}_{5}$, are possible to obtain through electrodeposition ${ }^{21}$.

The identified $\beta-\mathrm{Cu}-\mathrm{Zn}$ and $\gamma-\mathrm{Cu}-\mathrm{Zn}$ phases are consistent with composition data shown in Fig. 3, where all coatings contained 30 to $50 \% \mathrm{Cu}$ and 25 to $35 \% \mathrm{Zn}$. However, no peaks of Mo or oxidized species of this metal were observed, although these coatings had up to $8 \%$ of Mo, indicating that the electrodeposited Mo species are totally amorphous. On the other hand, diffraction patterns showed significant irregularity in background intensity, most evident in the range of $2 \theta$ from $50^{\circ}$ to $53^{\circ}$. This irregularity was attributed to the diffraction of plane (200) of the $\mathrm{Cu}$ with low crystallinity, which might have been caused by the introduction of amorphous Mo into the lattice of this metal. According to Gotou et al. ${ }^{17}$, molybdenum can be introduced into the crystal lattice of the copper, causing an enlarging of lattice space and leading to 
an amorphous structure. Therefore, the $\mathrm{Cu}-\mathrm{Zn}-\mathrm{Mo}$ coatings obtained in this work were a mixture of $\mathrm{Cu}-\mathrm{Zn}$ intermetallic phases and coppermolybdenum amorphous composites, as well as Mo oxides with fully amorphous characteristics.

\section{Conclusions}

In this work was studied the parameters for electrodeposition of the system $\mathrm{Cu}-\mathrm{Zn}-\mathrm{Mo}$ in citrate baths. The voltammetric profiles indicate that binary phases of $\mathrm{Cu}-\mathrm{Zn}$ and $\mathrm{Cu}-\mathrm{Mo}$ can be formed in potentials more negative than $-1.2 \mathrm{~V}$ together with hydrogen evolution. The morphologies of the coatings obtained in the potential of $-1.5 \mathrm{~V}$ were compact and presented small agglomerated particles forming larger cauliflower structures, and $\mathrm{Mo}, \mathrm{Cu}$ and $\mathrm{Zn}$ in these coatings ranged from 5 to $8 \%, 30$ to $40 \%$ and 20 to $28 \%$, respectively. Compositional analysis and XRD patterns showed that no ternary phases were formed, but rather a mixture of intermetallic $\mathrm{Zn}-\mathrm{Cu}$ phases and $\mathrm{Mo}-\mathrm{Cu}$ amorphous composite, as well as Mo oxides with totally amorphous characteristics.

\section{Acknowledgments}

The authors thank the Conselho Nacional de Desenvolvimento Científico e Tecnológico (CNPq), Fundação de Amparo à Pesquisa do Estado de São Paulo (FAPESP number 2018/16401-8), CEPID (2013/07296-2) and CAPES (finance code 001) for financial support.

\section{See Supplementary information.}

\section{References}

[1] Morales, J., Fernandez, G. T., Esparza, P., Gonzalez, S., Salvarezza, R. C., Arvia, A. J., A comparative study on the passivation and localized corrosion of $\alpha, \beta$, and $\alpha+\beta$ brass in borate buffer solutions containing sodium chloride-I. Electrochemical data, Corrosion Science 37 (2) (1995) 211-229. https://doi.org/10.1016/0010938X(94)00108-I.

[2] Lowenheim, F. A., Modern Electroplating, WileyInterscience, New York, 3rd ed., 1974.

[3] Gómez, E., Pellicer, E., Vallés, E., Influence of the bath composition and the $\mathrm{pH}$ on the induced cobaltmolybdenum electrodeposition, Journal of
Electroanalytical Chemistry 556 (2003) 137-145. https://doi.org/10.1016/S0022-0728(03)00339-5.

[4] Sanches, L. S., Domingues, S. H., Carubelli, A., Mascaro, L. H., Electrodeposition of Ni-Mo and Fe-Mo alloys from sulfate-citrate acid solutions, Journal of Brazilian Chemical Society 14 (4) (2003) 556-563. https://doi.org/10.1590/S0103-50532003000400011.

[5] Sanches, L. S., Domingues, S. H., Marino, C. E. B., Mascaro, L. H., Characterisation of electrochemically deposited Ni-Mo alloy coatings, Electrochemistry communication $6 \quad$ (6) (2004) 543-548. https://doi.org/10.1016/j.elecom.2004.04.002.

[6] Podlaha, E. J., Landolt, D., Induced codeposition: II. A mathematical model describing the electrodeposition of Ni-Mo alloys, Journal of The Electrochemical $\begin{array}{lllll}\text { Society. } & 143 \quad \text { (3) } \quad \text { (1996) }\end{array}$ https://doi.org/10.1149/1.1836553.

[7] Gómez, E., Pellicer, E., Duch, M., Esteve, J., Vallés, E., Molybdenum alloy electrodeposits for magnetic actuation, Electrochimica Acta 51 (16) (2006) 32143222. https://doi.org/10.1016/j.electacta.2005.09.010.

[8] Saravanan, P., Raja, V. S., Mukherjee, S., Effect of alloyed molybdenum on corrosion behavior of plasma immersion nitrogen ion implanted austenitic stainless steel, Corrosion Science 74 (2013) 106-115. https://doi.org/10.1016/j.corsci.2013.04.030.

[9] Liu, R., Yao, J., Zhang, Q., Yao, M. X., Collier, R., Effects of molybdenum content on the wear/erosion and corrosion performance of low-carbon Stellite alloys, Materials \& Design 78 (2015) 95-106. https://doi.org/10.1016/j.matdes.2015.04.030.

[10] Xia, M., Lei, T., Lv, N., Li, N., Synthesis and electrocatalytic hydrogen evolution performance of $\mathrm{Ni}$ Mo-Cu alloy coating electrode, International Journal of Hydrogen Energy 39 (10) (2014) 4797-4802. https://doi.org/10.1016/j.ijhydene.2014.01.091.

[11] Babu, M. V, Kumar, R. K., Prabhakar, O., Shankar, N. G., Simultaneous optimization of flame spraying process parameters for high quality molybdenum coatings using Taguchi methods, Surface and Coatings Technology $79 \quad(1-3) \quad$ (1996) 276-288. https://doi.org/10.1016/0257-8972(95)02453-0.

[12] Savitskii, E. M., Burkhanov, G. S., Physical metallurgy of refractory metals and alloys, Consultants Bureau, New York, 1st ed., 1970.

[13] Syed, R., Ghosh, S. K., Sastry, P. U., Sharma, G., Hubli, R. C., Chakravartty, J. K., Electrodeposition of thick metallic amorphous molybdenum coating from aqueous electrolyte, Surface Coatings Technology 261 
(2015)

15-20.

https://doi.org/10.1016/j.surfcoat.2014.11.073.

[14] Kazimierczak, H., Ozga, P., Socha, R. P., Investigation of electrochemical co-deposition of zinc and molybdenum from citrate solutions, Electrochimica $\begin{array}{llll}\text { Acta } & 104 & \text { (2013) } & \text { 378-390. }\end{array}$ https://doi.org/10.1016/j.electacta.2012.12.140.

[15] Gromboni, M. F., Mascaro, L. H., Optical and structural study of electrodeposited zinc selenide thin fi lms, Journal of Electroanalytical Chemistry 780 (2016) 360-366.

https://doi.org/10.1016/j.jelechem.2016.04.037.

[16] Kazimierczak, H., Ozga, P., Swiatek, Z., Bielanska, E., Characterisation of Zn-Mo alloy layers electrodeposited from aqueous citrate solution, Journal of Alloys and Compounds 578 (2013) 82-89. https://doi.org/10.1016/j.jallcom.2013.04.205.

[17] Gotou, M., Arakawa, T., Watanabe, N., Hara, T., Tomita, T., Hashimoto, A., Takanashi, H., Koiwa, I., Copper-molybdenum source ratio and complexing agent for high molybdenum content in electrodeposited $\mathrm{Cu}-$ Mo, Journal of The Electrochemical Society 161 (12) (2014)

D628-D631. https://doi.org/10.1149/2.0051412jes.

[18] Kazimierczak, H., Ozga, P., Berent, K., Kot, M., Microstructure and micromechanical properties of electrodeposited Zn-Mo coatings on steel, Journal of Alloys and Compounds 636 (2015) 156-164. https://doi.org/10.1016/j.jallcom.2015.02.165.

[19] de Almeida, M. R. H., Barbano, E. P., Zacarin, M. G., Brito, M. M., Tulio, P. C., Carlos, I. A., Electrodeposition of CuZn films from free-of-cyanide alkaline baths containing EDTA as complexing agent, Surface and Coatings Technology 287 (2016) 103-112. https://doi.org/10.1016/j.surfcoat.2015.12.079.

[20] Özdemir, R., Karahan, İ. H., Karabulut, O., A study on the electrodeposited $\mathrm{Cu}-\mathrm{Zn}$ alloy thin films, Metallurgical and Materials Transactions A 47 (11) (2016) 5609-5617. https://doi.org/10.1007/s11661-016$3715-0$

[21] Juskenas, R., Karpaviciene, V., Pakstas, V., Selskis, A., Kapocius, V., Electrochemical and XRD studies of $\mathrm{Cu}-\mathrm{Zn}$ coatings electrodeposited in solution with dmannitol, Journal of Electroanalytical Chemistry 602 (2) (2007)

https://doi.org/10.1016/j.jelechem.2007.01.004.

[22] Wang, X., Su, R., Aslan, H., Kibsgaard, J., Wendt, S., Meng, L., Dong, M., Huang, Y., Besenbacher, F., Tweaking the composition of NiMoZn alloy electrocatalyst for enhanced hydrogen evolution reaction performance, Nano Energy 12 (2015) 9-18. https://doi.org/10.1016/j.nanoen.2014.12.007.

[23] Luo, D., Hu, W., Wang, Y., Zhang, Y., Wang, G., Study on amorphous Ni-Mo-Fe-Zn coating electrocatalyst for hydrogen evolution in alkaline solution, Journal of Mechanical Science and Technology 12 (3) (1996) 190-194.

[24] Arul Raj, I., On the catalytic activity of NiMoFe composite surface coatings for the hydrogen cathodes in the industrial electrochemical production of hydrogen, Applied Surface Science 59 (3-4) (1992) 245-252. https://doi.org/10.1016/0169-4332(92)90124-G.

[25] Gamburg, Y. D., Zangari, G., Theory and Practice of Metal Electrodeposition, Springer, New York. 1st ed., 2011.

[26] Loto, C. A., Electrodeposition of zinc from acid based solutions: A review and experimental study, Asian Journal Applied Sience 5 (6) (2012) 314-326. https://doi.org/10.3923/ajaps.2012.314.326.

[27] Beltowska-Lehman, E., Electrodeposition of protective Ni-Cu-Mo coatings from complex citrate solutions, Surface Coatings Technology 151-152 (2002) 440-443. https://doi.org/10.1016/S02578972(01)01613-9.

[28] Silva, F. L. G., Do Lago, D. C. B., D’Elia, E., Senna, L. F., Electrodeposition of $\mathrm{Cu}-\mathrm{Zn}$ alloy coatings from citrate baths containing benzotriazole and cysteine as additives, Journal of Applied Electrochemistry 40 (11) (2010) 2013-2022. https://doi.org/10.1007/s10800010-0181-Z

[29] Slupska, M., Ozga, P., Electrodeposition of Sn-Zn$\mathrm{Cu}$ alloys from citrate solutions, Electrochimica Acta 141 (2014) 149-160. https://doi.org/10.1016/j.electacta.2014.07.039.

[30] Alonso, C., Pascual, M. J., Abruña, H. D., Influence of organic adsorbates on the under and overpotential deposition of copper on polycrystalline platinum electrodes, Electrochimica Acta 42 (11) (1997) 17391750. https://doi.org/10.1016/S0013-4686(96)00374-X.

[31] Cruywagen, J. J., Rohwer, E. A., Wessels, G. F. S., Molybdenum(VI) complex formation-8. Equilibria and thermodynamic quantities for the reactions with citrate, Polyhedron 14 (23-24) (1995) 3481-3493. https://doi.org/10.1016/0277-5387(95)00210-J.

[32] Field, T. B., McCourt, J. L., McBryde, W. A. E., Composition and stability of iron and copper citrate complexes in aqueous solution, Canadian Journal of $\begin{array}{lllll}\text { Chemistry } & 52 & \text { (17) (1974) 3119-3124. }\end{array}$ https://doi.org/10.1139/v74-458. 
[33] Luo, Z., Miao, R., Huan, T. D., Mosa, I. M., Poyraz, A. S., Zhong, W., Cloud, J. E., Kriz, D. A., Thanneeru, S., He, J., Zhang, Y., Ramprasad, R., Suib, S. L., Mesoporous MoO-x material as an efficient electrocatalyst for hydrogen evolution reactions, Advanced Energy Materials 6 (16) (2016) 1600528. https://doi.org/10.1002/aenm.201600528. 